\title{
UJI ADAPTASI 5 VARIETAS UNGGUL BARU PADI DI KABUPATEN MERAUKE
}

\author{
(Adaptation Test of 5 New Improved Rice Varieties in Merauke Regency) \\ Fransiskus Palobo, Adnan \\ Balai Pengkajian Teknologi Pertanian Papua \\ J1. Yahim No. 49, Sentani, Jayapura - Papua 99352 \\ Telp (0967) 592179, Fax (0967) 591235 \\ e-mail : adnan.msi@pertanian.go.id; aalbahry@yahoo.com
}

Article Submitted : 16-02-2019

Article Accepted : 03-04-2019

\begin{abstract}
The research aim is to conduct an adaptation test of 5 new improved rice varieties and to obtain suitable varieties for a specific location in Merauke Regency. Breeder seeds were used as materials. The location was held in 4 different villages as replication. Experimental design is onefactor randomized block design with variety used as factor design: Aek Sibundong, Inpago 1, Inpari 17, Inpari 18 dan Inpari 19. The results show that Inpari 17 and Inpari 19 gain the best result of productivity, which is 4.5 and $4.2 \mathrm{ton} /$ ha, respectively. The productivity correlated to panicle length (0.48), the number of productive tillers (0.39), and the number of filled grains $(0.43)$. These results indicate Inpari 17 and Inpari 19 adapted to Merauke regency agroecosystem and their productivity is still possible to be increased as similar to its characteristics potential.
\end{abstract}

Keywords: new improved varieties, Merauke, adaptation test, breeder seed.

\section{PENDAHULUAN}

Perakitan varietas unggul baru (VUB) padi dilakukan agar tersedia varietas yang mampu beradaptasi baik dan bertahan lama sesuai dengan agroekosistem pengembangan. Setiap VUB membutuhkan persyaratan spesifik agar hasil maksimal (Silitonga, 2004). Uji multilokasi menjadi menjadi salah satu syarat mutlak untuk menseleksi genotipe sebagai bahan penyusun VUB yang beradaptasi secara luas dan spesifik (Sitaresmi et al., 2016).

VUB yang sudah dilepas tetap perlu diuji adaptasi pada kondisi spesifik lokasi. Uji multilokasi mustahil mencakup semua jenis kondisi ekosistem yang ada. Lokasi berbeda memiliki kondisi spesifik berbeda seperti tantangan terhadap hama ganjur, bakteri hawar daun, hawar daun jingga, blas daun, blas leher, daun bergaris putih, wereng batang coklat, tungro, kekeringan, keracunan $\mathrm{Al}$, keracunan $\mathrm{Fe}$, salinitas, suhu rendah, dan naungan (Sitaresmi et al., 2013).

Pada penelitian ini, 5 VUB padi yang dilepas oleh Kementerian Pertanian (Kementan) diuji adaptasi di kabupaten Merauke. Lokasi uji tersebar di 4 kampung pada 3 distrik sentra produksi beras di kabupaten Merauke (Gambar 1). Kabupaten Merauke merupakan sentra produksi beras di provinsi Papua. Produksi padi sawah di kabupaten ini pada tahun 2015 adalah 156,489 ton atau $90.1 \%$ dari total produksi di provinsi Papua (BPS, 2018). Percepatan penggunaan VUB padi di sentra produksi tersebut diharapkan dapat mempertahankan bahkan meningkatkan produksi padi.

Di tahun 2014 suhu udara rata-rata di Kabupaten Merauke adalah sebesar $26.7^{\circ} \mathrm{C}$ dengan suhu terendah sebesar $21.0^{\circ} \mathrm{C}$ pada 
bulan September dan suhu tertinggi terjadi pada bulan Desember sebesar $32.8^{\circ} \mathrm{C}$. Jumlah hari hujan adalah 174 hari dengan curah hujan tertinggi pada bulan April dengan besar $482.7 \mathrm{~mm}$ dan terendah bulan Oktober sebesar $2.6 \mathrm{~mm}$ (BPS, 2015). Kondisi ekosistem kabupaten Merauke tersebut bisa jadi berbeda dengan kondisi saat perakitan VUB berlangsung sehingga uji adaptasi menjadi penting untuk dilakukan.

Tujuan penelitian adalah melakukan uji adaptasi terhadap 5 VUB padi untuk memperoleh varietas yang sesuai dengan kondisi spesifik lokasi kabupaten Merauke.

\section{METODE PENELITIAN}

\section{Bahan}

Varietas unggul baru (VUB) padi yang digunakan dalam penelitian ini adalah Aek Sibundong, Inpago 1, Inpari 17, Inpari 18 dan Inpari 19 dengan kelas benih penjenis. Karakteristik VUB tersebut ditampilkan pada Tabel 1.

Tabel 1. Karakteristik varietas unggul baru padi

\begin{tabular}{llccccc}
\hline \multirow{2}{*}{ No } & \multirow{2}{*}{ Parameter } & \multicolumn{5}{c}{ Varietas } \\
\cline { 3 - 7 } & & $\begin{array}{c}\text { Aek } \\
\text { Sibundong }\end{array}$ & Inpago 1 & Inpari 17 & Inpari 18 & Inpar 19 \\
\hline 1 & Tinggi tanaman (cm) & 112 & 107 & 105 & 93 & 102 \\
2 & Jumlah anakan produktif & 18 & 16 & 18 & 15 & 15 \\
3 & Produktifitas (ton/ha) & 6 & 4.9 & 6.2 & 6.7 & 6.7 \\
4 & Tahun & 2006 & 2011 & 2011 & 2011 & 2011 \\
5 & Tekstur nasi & Pulen & pulen & pera & pulen & pulen \\
\hline
\end{tabular}

Sumber: BBPadi (2019)

\section{Lokasi dan Waktu Penelitian}

Penelitian dilaksanakan di 4 kampung di kabupaten Merauke pada bulan Januari sampai Mei 2014 (Tabel 2). Pemilihan lokasi dilakukan secara sengaja untuk mendukung program Kementan dalam mempercepat ketersediaan benih VUB di setiap sentral pengembangan padi di kabupaten Merauke.

Tabel 2. Lokasi Penelitian

\begin{tabular}{|c|c|c|c|c|}
\hline No & Distrik & Kampung & $\begin{array}{l}\text { Altitude* } \\
\text { (m dpl) }\end{array}$ & $\begin{array}{l}\text { Produktifitas* } \\
\text { (ton } / \text { ha) }\end{array}$ \\
\hline 1 & Kurik & Kurik Harapan & $5-30$ & 6.45 \\
\hline 2 & Semangga & Kuper & $4-20$ & 4.03 \\
\hline 3 & Tanah Miring & Sumber Harapan & $6-44$ & 6.11 \\
\hline 4 & Tanah Miring & Waningaf Miraf & $6-44$ & 6.11 \\
\hline
\end{tabular}

*sumber: BPS (2015): produktifitas padi rata-rata tahun 2014

\section{Metode Penelitian}

Penelitian menggunakan rancangan acak kelompok satu faktorial yaitu varietas dengan 5 anak faktor: a. Aek Sibundong, b. Inpago 1, c. Inpari 17, d. Inpari 1, e. Inpar 19. Lokasi dijadikan sebagai ulangan sebanyak 4 kampung (Tabel 2).
Luas petak percobaan untuk masingmasing perlakuan adalah $25 \times 50 \mathrm{~m}$. Sistem tanam menggunakan jajar legowo 4:1 (40:20:10 cm) yang merupakan teknologi unggulan Badan Litbang Kementan (Ikhwani et al., 2013). 


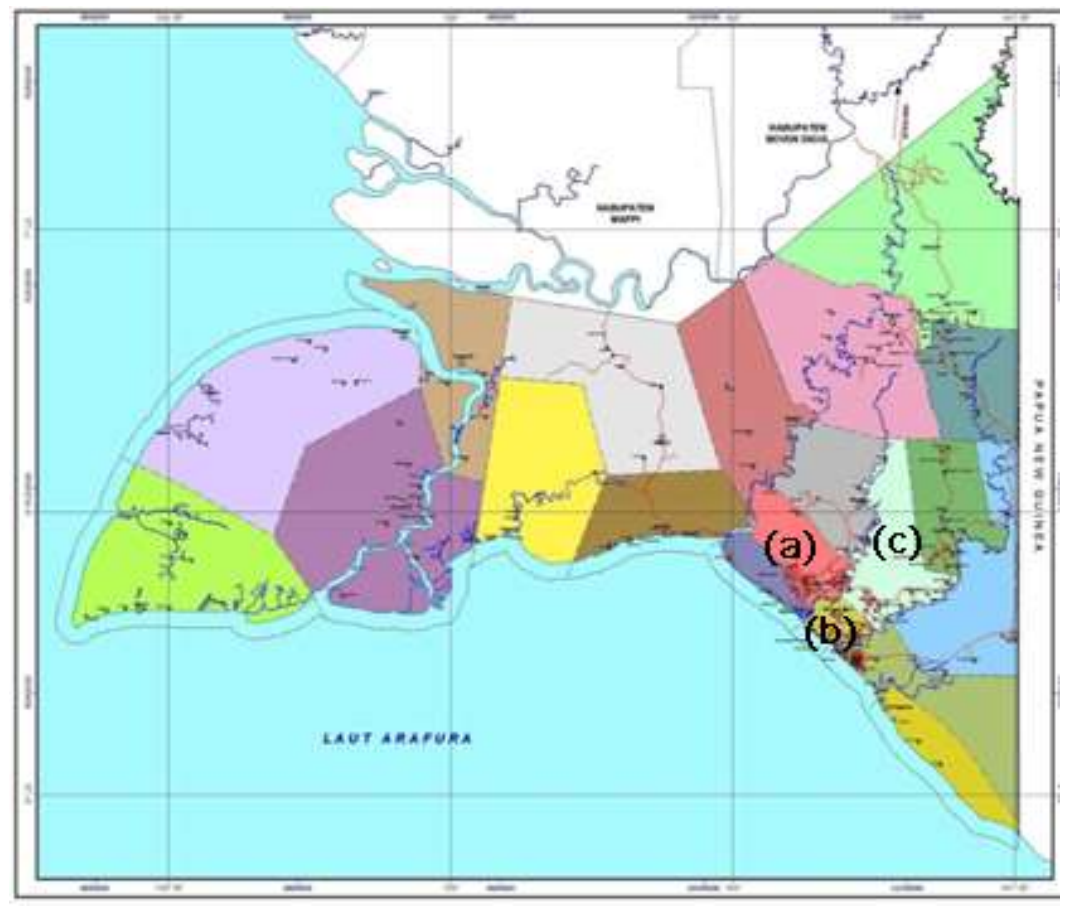

Peta skala 1:1,250,000; sumber: BPS (2015)

Gambar 1. Lokasi penelitian di distrik: (a) Kurik, (b) Semangga, (c) Tanah Miring, Kabupaten Merauke

Dosis pupuk ditentukan berdasarkan analisis tanah menggunakan Perangkat Uji Tanah Sawah (PUTS) (Jamil et al., 2014).
Rekomendasi dosis pupuk di lokasi penelitian berdasarkan PUTS versi 1.0 ditampilkan pada Tabel 3.

Tabel 3. Dosis pupuk yang digunakan dalam penelitian

\begin{tabular}{clccc}
\hline \multirow{2}{*}{ No } & \multirow{2}{*}{ Kampung } & Dosis $(\mathrm{kg} / \mathrm{ha})$ \\
\cline { 2 - 5 } & & Urea & NPK & $\mathrm{P}$ \\
\hline 1 & Kurik Harapan & 200 & 250 & 100 \\
2 & Kuper & 200 & 250 & 50 \\
3 & Sumber Harapan & 200 & 250 & 75 \\
4 & Waningaf Miraf & 150 & 250 & 100 \\
\hline
\end{tabular}

\section{Parameter Penelitian}

Adapun parameter yang diukur adalah: a. Tinggi tanaman pada fase vegetatif 45 hari setelah tanam (HST), b. Jumlah anakan produktif, c. Panjang malai, d. Jumlah gabah hampa, e. Jumlah gabah isi, f. Produktifitas berdasarkan bobot gabah kering giling (GKG) dengan kadar air 14\%. Penghitungan setiap parameter, kecuali produktifitas, dilakukan pada 10 sampel tanaman dan hasil merupakan nilai rata-rata. Produktifitas dihitung dengan melakukan teknik ubinan khusus untuk jajar legowo 4:1 yaitu 2.25x5 m dengan 3 ulangan dan hasil merupakan nilai rata-rata.

\section{Analisis Statistik}

Data diolah menggunakan aplikasi $\mathrm{R}$ versi 3.5.2. Analisis sidik ragam (Anova) dilakukan untuk mendapatkan nilai uji $\mathrm{F}$ pada taraf $5 \%$ dan nilai peluang, kemudian 
dilanjutkan analisis lanjut berdasarkan beda nyata terkecil (BNT) pada taraf 5\%. Hasil parameter agronomi dan produktifitas dibandingkan dengan hasil rata-rata varietas tersebut untuk mendapatkan gambaran daya adaptasi pada kondisi spesifik lokasi di kabupaten Merauke. Analisis korelasi dilakukan antar parameter pengamatan menggunakan metode Pearson. Perbedaan hasil ditampilkan sebagai persentase (\%), dihitung berdasarkan perbedaan parameter agronomi dan produktifitas varietas uji adaptasi terhadap karakteristik VUB padi.

\section{HASIL DAN PEMBAHASAN}

\section{Parameter agronomi dan produktifitas}

Analisis sidik ragam menunjukkan perlakuan varietas berbeda nyata pada parameter panjang malai. Sedangkan perlakuan varietas berbeda sangat nyata pada parameter tinggi tanaman, jumlah anakan produktif, gabah hampa, gabah isi dan produktifitas (Tabel 4).

Tabel 4. Ringkasan sidik ragam

\begin{tabular}{llcrc}
\hline No & Parameter & F value & $\operatorname{Pr}(>\mathrm{F})$ & CV \\
\hline 1 & Tinggi tanaman & 11.12 & $0.000215^{* *}$ & 9.98 \\
2 & Jumlah anakan produktif & 10.01 & $0.000376^{* *}$ & 10.90 \\
3 & Panjang malai & 3.457 & $0.0342^{*}$ & 6.38 \\
4 & Gabah hampa & 5.96 & $0.00446^{* *}$ & 27.76 \\
5 & Gabah isi & 10.89 & $0.000241^{* *}$ & 15.93 \\
6 & Produktifitas & 47.22 & $2.52 \mathrm{E}-08^{* *}$ & 7.53 \\
\hline
\end{tabular}

Keterangan : *berbeda nyata; $*$ berbeda sangat nyata pada taraf $5 \%$

Tinggi tanaman terbesar adalah Inpari $19(104.5 \mathrm{~cm})$ tetapi tidak berbeda nyata dengan varietas lainnya kecuali Inpari 17. Nilai terendah tinggi tanaman adalah Inpari $17(66.5 \mathrm{~cm})$. Jumlah anakan produktif

Tabel 5. Karakter agronomi dan produktifitas

\begin{tabular}{lccccc}
\hline \multirow{2}{*}{ Parameter } & \multicolumn{5}{c}{ Varietas } \\
\cline { 2 - 6 } & Aek Sibundong & Inpago 1 & Inpari 17 & Inpari 18 & Inpari 19 \\
\hline Tinggi tanaman (cm) & $103.3 \mathrm{a}$ & $98.0 \mathrm{a}$ & $66.5 \mathrm{~b}$ & $96.8 \mathrm{a}$ & $104.5 \mathrm{a}$ \\
Jumlah anakan & $17.0 \mathrm{~b}$ & $14.6 \mathrm{~b}$ & $22.5 \mathrm{a}$ & $16.8 \mathrm{~b}$ & $16.3 \mathrm{~b}$ \\
produktif & $24.3 \mathrm{~b}$ & $24.9 \mathrm{~b}$ & $25.8 \mathrm{ab}$ & $24.4 \mathrm{~b}$ & $27.9 \mathrm{a}$ \\
Panjang malai (cm) & $37.5 \mathrm{bc}$ & $28.9 \mathrm{c}$ & $43.7 \mathrm{bc}$ & $56.8 \mathrm{ab}$ & $69.4 \mathrm{a}$ \\
Gabah hampa & $76.8 \mathrm{~b}$ & $75.1 \mathrm{~b}$ & $83.2 \mathrm{~b}$ & $78.3 \mathrm{~b}$ & $130.0 \mathrm{a}$ \\
Gabah isi & $2.8 \mathrm{c}$ & $3.4 \mathrm{~b}$ & $4.5 \mathrm{a}$ & $2.4 \mathrm{c}$ & $4.2 \mathrm{a}$ \\
Produktifitas (ton/ha) &
\end{tabular}

Keterangan: Angka pada baris yang sama diikuti oleh huruf sama tidak berbeda nyata pada uji BNT pada $\operatorname{taraf} \alpha 5 \%$

Parameter panjang malai menunjukkan bahwa Inpari 19 memberikan hasil tertinggi sebesar $27.9 \mathrm{~cm}$ dan berbeda nyata dengan varietas lain kecuali Inpari 17. Nilai terendah tertinggi terdapat pada varietas Inpari 17 (22.5) dan berbeda nyata dengan varietas lainnya. Inpago 1 memiliki jumlah anakan produktif terendah sebesar 14.6. 
varietas lain kecuali Inpari 18. Sedangkan Inpago 1 memberikan hasil gabah hampa terendah sebesar 28.9. Gabah isi terbanyak sebanyak 130.0 terdapat pada varietas Inpari 19 dan berbeda nyata dengan varietas lainnya. Sedangkan Inpago 1 memiliki gabah isi terendah dengan nilai 75.1. Produktifitas tertinggi terdapat pada varietas Inpari 17 sebesar 4.5 ton/ ha serta berbeda nyata dari varietas lainnya kecuali varietas Inpari 19 sebesar 4.2 ton/ ha. Sedangkan Inpari 18 memberikan produktifitas terendah sebesar 2.4 ton/ ha.

\section{Korelasi antar parameter}

Pada Tabel 6 disajikan korelasi antar parameter agronomi dan produktifitas.

Tabel 6. Korelasi antar parameter

\begin{tabular}{|c|c|c|c|c|c|c|}
\hline Parameter & $\begin{array}{l}\text { Jumlah } \\
\text { anakan } \\
\text { produktif }\end{array}$ & $\begin{array}{l}\text { Gabah } \\
\text { hampa }\end{array}$ & Gabah isi & $\begin{array}{l}\text { Produktifitas } \\
\quad \text { (ton/ha) }\end{array}$ & $\begin{array}{c}\text { Panjang } \\
\text { malai }(\mathrm{cm})\end{array}$ & $\begin{array}{l}\text { Tinggi } \\
\text { tanaman } \\
(\mathrm{cm})\end{array}$ \\
\hline $\begin{array}{l}\text { Jumlah anakan } \\
\text { produktif }\end{array}$ & 1.00 & & & & & \\
\hline Gabah hampa & -0.02 & 1.00 & & & & \\
\hline Gabah isi & -0.01 & $0.67 * *$ & 1.00 & & & \\
\hline Produktifitas & 0.39 & 0.17 & 0.43 & 1.00 & & \\
\hline Panjang malai & -0.07 & $0.55^{*}$ & $0.58 * *$ & $0.48^{*}$ & 1.00 & \\
\hline Tinggi tanaman & $-0.51 *$ & -0.01 & 0.22 & $-0.46^{*}$ & -0.15 & 1.00 \\
\hline
\end{tabular}

Uji korelasi menujukkan bahwa gabah isi berkorelasi kuat, positif dan berbeda sangat nyata dengan panjang malai dan gabah hampa. Adapun produktifitas berkorelasi sedang, negatif dan berbeda nyata dengan panjang malai; berkorelasi sedang, negatif dan berbeda nyata dengan tinggi tanaman; serta berkorelasi sedang, positif tetapi tidak berbeda nyata dengan jumlah anakan produktif dan gabah isi.

\section{Perbedaan Hasil}

Aek Sibundong, Inpago 1 dan Inpari 17 pada uji adaptasi memiliki nilai tinggi tanaman lebih rendah dibandingkan nilai karakteristik VUB, sedangkan nilai tinggi tanaman pada Inpari 18 dan Inpari 19 sedikit lebih besar dibandingkan nilai karakteristik VUB. Perbedaan tinggi tanaman terbesar adalah pada varietas Inpari 17 sebesar $-36.7 \%$ (Tabel 7).

Tabel 7. Perbedaan hasil

\begin{tabular}{|c|c|c|c|c|c|c|}
\hline \multirow[b]{2}{*}{ No } & \multirow[b]{2}{*}{ Parameter } & \multicolumn{5}{|c|}{ Varietas } \\
\hline & & $\begin{array}{c}\text { Aek } \\
\text { Sibundong }\end{array}$ & $\begin{array}{c}\text { Inpago } \\
1\end{array}$ & $\begin{array}{c}\text { Inpari } \\
17 \\
\end{array}$ & $\begin{array}{c}\text { Inpari } \\
18\end{array}$ & Inpari 19 \\
\hline 1 & Tinggi tanaman $(\%)$ & -7.8 & -8.4 & -36.7 & 4.0 & 2.5 \\
\hline 2 & Jumlah anakan produktif (\%) & -5.6 & -9.1 & 25.0 & 11.7 & 8.3 \\
\hline 3 & Produktifitas (\%) & -53.8 & -30.9 & -26.9 & -63.6 & -37.3 \\
\hline \multicolumn{7}{|c|}{ terangan: angka negatif (-) menunjukkan nilai uji adaptasi lebih rendah daripada nilai karakteristik VUB } \\
\hline \multirow{3}{*}{\multicolumn{3}{|c|}{$\begin{array}{l}\text { Pada parameter anakan produktif, } \\
\text { Aek Sibundong dan Inpago } 1 \text { lebih rendah } \\
\text { sedangkan Inpari 17, Inpari } 18 \text { dan Inpari } 19 \\
\text { lebih banyak dibandingkan nilai karakteristik }\end{array}$}} & \multirow{2}{*}{\multicolumn{4}{|c|}{$\begin{array}{l}\text { VUB. Varietas Inpari } 17 \text { memiliki perbedaan } \\
\text { terbesar sebanyak } 25.0 \% \text {. } \\
\text { Semua varietas memiliki }\end{array}$}} \\
\hline & & & & & & \\
\hline & & & & & & ngke \\
\hline
\end{tabular}


karakteristik VUB. Perbedaan terendah terdapat pada Inpari 17 (-26.9\%) sedangkan perbedaan tertinggi adalah varietas Inpari 18 $(-63.6 \%)$.

Inpari 19 menunjukkan penampilan agronomi yang cenderung lebih tinggi dibandingkan varietas lain, seperti pada parameter tinggi tanaman $(104.5 \mathrm{~cm})$, panjang malai $(27.9 \mathrm{~cm})$, dan jumlah gabah isi (130). Inpari 19 menghasilkan produktifitas tertinggi kedua (4.2 ton/ ha) tetapi tidak berbeda nyata dengan Inpari 17. Namun, Inpari 19 tidak menunjukkan hasil terbaik pada parameter jumlah anakan produktif dan gabah hampa (Tabel 5). Data tersebut menunjukkan bahwa varietas unggul tidak selalu menunjukkan hasil terbaik pada setiap parameter uji.

Pada umumnya, produktivitas menjadi fokus utama pada uji multilokasi VUB padi. Namun, karakteristik lain tetap perlu untuk diketahui seperti tinggi tanaman. Parameter ini penting diperhatikan untuk mengurangi resiko tanaman rebah ketika menghadapi situasi spesifik lokasi seperti daerah dengan kontur miring atau intensitas angin tinggi (Sa'diyah et al., 2014).

Penelitian sebelumnya menunjukkan galur atau varietas padi memiliki karakter parameter utama yang berbeda. Galur BP11252-2-PN-12-2-2-2-1-7-MR-6

memiliki keunggulan di parameter jumlah anakan, Galur BP3300-2C-2-3 menghasilkan jumlah gabah isi dan gabah hampa tertinggi, galur IPB-6 unggu pada karakter tinggi tanaman, sedangkan varietas dengan karakter produktifitas tertinggi adalah Cimelati dan Inpari (Sa'diyah et al., 2014).

Produktifitas berkorelasi positif dan berbeda nyata terhadap panjang malai $\left(0.48^{*}\right)$ serta berkorelasi positif terhadap jumlah anakan produktif (0.39) dan gabah isi (0.43) (Tabel 6). Nilai tersebut menunjukkan bahwa peningkatan jumlah anakan produktif, panjang malai dan gabah isi akan meningkatkan produktifitas. Kondisi ini didukung oleh nilai korelasi positif dan berbeda sangat nyata panjang malai terhadap gabah isi $\left(0.58^{* *}\right)$ yang bisa diintepretasikan sebagai peningkatan panjang malai akan meningkatkan jumlah gabah isi.

Data korelasi pada penelitian ini didukung oleh penelitian sebelumnya yang memberikan hasil bahwa produktifitas berkorelasi positif dengan jumlah anakan produktif $\left(0.41^{* *}\right)$, panjang malai $(0.18)$ dan gabah isi $(0.54 * *)$ (Syafii et al., 2018). Hasil tersebut mengindikasikan bahwa varietas yang memiliki karakter jumlah anakan produktif, panjang malai dan jumlah gabah isi tinggi akan memberikan produktifitas yang tinggi.

Berdasarkan penampilan parameter agronomi dan hasil produksi, Inpari 17 dan Inpari 19 memberikan hasil terbaik. Namun, produktifitas semua varietas uji (Tabel 5) berada dibawah nilai karakteristik VUB (Tabel 1). Perbedaan produktifitas tersebut berkisar antara -26.9 sampai $-63.6 \%$. Kondisi ini diduga karena kondisi agroekosistem perakitan varietas tersebut tidak mencakup spesifik lokasi di kabupaten Merauke.

Namun, produktifitas uji adaptasi yang relatif rendah tersebut masih bisa ditingkatkan. Gabah hampa pada penelitian ini relatif tinggi, berkisar 38.5-72.6\% dibandingkan dari jumlah gabah isi (Tabel 5). Sebagai pembanding pada penelitian lain, gabah hampa berada pada kisaran 11.742.5\% dibandingkan jumlah gabah isi (Kartina et al., 2016). Persentase gabah hampa yang tinggi tersebut diduga akibat serangan hama walang sangit pada lokasi penelitian.

Hama walang sangit berpotensi merugikan jika berada dalam jumlah banyak. Tipe mulut hama tersebut adalah menusuk menghisap. Walang sangit menghisap cairan yang terdapat dalam gabah ketika belum keras pada fase pengisian biji sehingga banyak didapat gabah hampa saat panen (Nasution et al., 2017). Walang sangit berpotensi menurunkan produksi gabah sampai $23.9 \%$ pada tanaman kontrol dibandingkan tanaman yang mendapatkan perlakuan pestisida nabati (Afifah et al., 2015). 


\section{KESIMPULAN}

Inpari 17 dan Inpari 19 memberikan penampilan terbaik, tetapi semua varietas berada dibawah penampilan seharusnya sesuai karakteristik VUB. Potensi hasil panen masih bisa ditingkatkan jika persentase gabah hampa dikurangi. Pengembangan VUB harus terus dilakukan agar VUB tersebut dapat beradaptasi dengan agroekosistem kabupaten Merauke dan memberikan hasil sesuai karakteristik.

\section{DAFTAR PUSTAKA}

Afifah, F., Rahayu, Y.S., Faizah, U., 2015. Efektivitas Kombinasi Filtrat Daun Tembakau (Nicotiana tabacum) dan Filtrat Daun Paitan (Thitonia diversifolia) sebagai Pestisida Nabati Hama Walang Sangit (Leptocorisa oratorius) pada Tanaman Padi. LenteraBio 40, 25-31.

BBPadi, 2019. Daftar Varietas Unggul [WWW Document]. URL http://www.litbang.pertanian.go.id/vari etas/ (accessed 2.6.19).

BPS, 2018. Provinsi Papua Dalam Angka 2018. BPS Provinsi Papua, Jayapura, Papua.

BPS, 2015. Merauke Dalam Angka 2015. Badan Pusat Statistik Kabupaten Merauke, Merauke.

Ikhwani, Pratiwi, G.R., Paturrohman, E., Makarim, A.K., 2013. Peningkatan Produktivitas Padi Melalui Penerapan Jarak Tanam Jajar Legowo. Iptek Tanam. Pangan 8, 72-79.

Jamil, A., Abdulrachman, S., Syam, M., 2014. Dinamika Anjuran Dosis Pemupukan N, P , dan K pada Padi Sawah. IPTEK Tanam. Pangan 9, 6377.
Kartina, N., Wibowo, B.P., Widyastuti, Y., Rumanti, I.A., Satoto, 2016. Korelasi dan Sidik Lintas Karakter Agronomi Padi Hibrida. J. Ilmu Pertan. Indones. 21, 76-83. https://doi.org/10.18343/jipi.21.2.76

Nasution, M.N.H., Syarif, A., Anwar, A., Silitonga, Y.W., 2017. Pengaruh Beberapa Jenis Bahan Organik Terhadap Hasil Tanaman Padi (Oryza sativa L) Metode SRI. J u r n a 1 A g r o h i t a $1,28-37$.

Sa'diyah, H., Sitaresmi, R., Hadi, D.F., 2014. Karakterisasi Galur Harapan Padi Sawah Hasil Penelitian Konsorsium Padi Nasional. Bionatura-Jurnal Ilmuilmu Hayati dan Fis. 16, 142-145.

Silitonga, T.S., 2004. Pengelolaan dan Pemanfaatan Plasma Nutfah Padi di Indonesia. Bul. Plasma Nutfah 10, 5671.

Sitaresmi, T., Gunarsih, C., Nugraha, Y., Abdullah, B., Hanarida, I., Aswidinnoor, H., Daradjat, A.A., 2016. Interaksi Genotipe x Lingkungan untuk Hasil Gabah Padi Sawah. Penelit. Pertan. Tanam. Pangan 35, 89-98.

Sitaresmi, T., Wening, R.H., Rakhmi, A.T., Yunani, N., Susanto, U., 2013. Pemanfaatan Plasma Nutfah Padi Varietas Lokal dalam Perakitan Varietas Unggul. IPTEK Tanam. Pangan 8, 22 30 .

Syafii, M., Purwoko, B.S., Dewi, I.S., Suwarno, W.B., 2018. Karakter Agronomi Galur Padi Dihaploid Asal Kultur Antera Hasil Persilangan Three Way Cross. J. Agron. Indones. 46, 9-16. 